The Open Civil Engineering Journal
CrossMark
Content list available at: www.benthamopen.com/TOCIEJ/
DOI: $10.2174 / 1874149501610010794$

RESEARCH ARTICLE

\title{
Engineering Project Real-time Objective Monitor Based on Grid Management and Buffer Analysis
}

\author{
Heyun Dong ${ }^{*}, 1,2$, Jian Zhang ${ }^{2}$ and Shisen $\mathrm{Lv}^{2}$ \\ ${ }^{I}$ Tsinghua University, No. 30, Shuangqing Road, Haidian District, Beijing, China \\ ${ }^{2}$ Electric Power Planning \& Engineering Institute, No. 65, Ande Road, Xicheng District, Beijing, China
}

Received: April 13,2016

Revised: July 08,2016

Accepted: August 22, 2016

\begin{abstract}
Engineering projects often face a great number of uncertainties which will lead projects to deviate from the anticipated objective. This paper carried out a detailed study on real-time monitoring of objective deviation in engineering projects, and it will help project managers monitor the state of engineering project better. A Grid Management (GM) method was used to set up a monitor structure, and the real-time monitor grid structure was constructed in level, milestone and objective dimensions. The buffer analysis method was designed to measure the level of objective deviation. The objective deviation level is based on the result of the grid cell buffer analysis. The principal part construction of Shenyang Olympic Tennis court was selected as the example to illustrate the real-time monitor process in detail. The results indicated that the proposed real-time objective monitor method makes it possible for project manager to real-time monitor all the main objectives in one model and carry out management, and decision-making in a more macro perspective.
\end{abstract}

Keywords: Buffer analysis, Engineering project management, Fixed objective (FO), Grid management (GM), March objective (MO), Objective deviation, Real-time monitor.

\section{INTRODUCTION}

The complex, dynamic and continually changing characteristics of the construction process have been recognized as an important contributor to the high rates of deviation [1], such as project delay, cost overrun and an increase in the number of accidents. Therefore, keeping the project in step with the expected plan is an important goal that many scholars and project administrators are concerned with. Some project control concepts or theories have been applied to help project managers to reduce project deviation with the development of frameworks and models. Management by objectives (MBO) was put forward by American management guru Peter Drucker in 1954 and has been widely applied in the field of engineering project management. The engineering project is usually defined as a set of tasks or activities under specific objectives. Many researchers have focused on the planning and monitoring the problem of quality objective, schedule objective and cost objective. Wu et al. [2] added safety objective and environment objective to manage scope and proposed "Engineering project five main objectives". Meanwhile, the participants' satisfaction has been added as one of the management objective in some researches [3]. In recent years, there are number of research achievements about engineering project objectives control. For example, the critical path method (CPM) achieves the goal of schedule objective optimization through accurately manage the critical path. Gardoni used adapted Bayesian network method to forecast the schedule of key milestone and project completion time [4]. Earned value management (EVM) is a commonly used method what performs dynamic calculation of project schedule and cost objective by comparing the three main indicators "planned value (PV), actual cost (AC), earned value (EV)" and their derivative index [5]. Based on the EVM theory, many scholars have derived some objective optimization algorithms such as

\footnotetext{
* Address correspondence to this author at the Tsinghua University No. 30, Shuangqing Road, Haidian District, Beijing, China; Tel: +86 13810009479; E-mail: heyd1111@126.com
} 
Planned Value Method (PVM), Earned Duration Method (EDM). Some project control concepts or theories have been applied to help project managers to reduce project deviation with the development of frameworks and models [6, 7]. Monghasemi believed that multi-objective interest conflict is a main problem in making objective plan in project decision making and planning phase. Therefore, he built a multi-objective genetic algorithm (MOGA) decision model to research the trade-off and priorities problem of schedule-cost-quality objectives [8]. Cristobal [9] established a 0-1 integer programming model which enables projects to meet the quality output standard, time and budget objectives. Seyedhoseini et al. introduced an objective for selecting a set of project risk response actions that minimizes the undesirable deviation from achieving the project goal [10].

Grid technology is an important information technology developed in recent years. It can provide great processing capacity and achieve maximum information integration and sharing [11]. In 1998, the father of the grid, American scientist Ian Foster believed that grid technology would fuse the high speed internet, high-performance computer, large database, sensors and remote equipment together [12]. These features can provide people with more resources and interactive functions. In the computer field, grid technology is mainly used in distributed supercomputing, data intensive computing, tele-immersion and information integration [13]. In addition, high performance computing grids are also in great demand in many industries such as energy, transportation, weather, water conservation, agriculture, forestry, education, environmental protection [14]. GM is an innovative management concept evolved from grid technology, which divides the managed object into grid cells according to a certain standard. By using computer information technology or the grid cell coordination mechanism, the managed object can achieve efficient information communication, share the resources of the organization transparently, and finally achieve integration of organization resources, thus improve the efficiency of management [15]. Current researches on GM have gradually permeated the fields of computer information management, business management, market management, urban management and administrative management. Gor et al. [13] argued that the traditional grid concept in computer science was not suitable for enterprise. He extended the grid structure from the computer components and operating system to the institution, decision-making and influence of the environment. Then he put forward a GM system based on the enterprise workflow: Unified GM and Data Architecture (UGanDA). In the market management field, Intel Corporation divided the market into grid and further regional markets to provide rapid customer response, better customer service and optimized local market activity in early 2005 [16]. In China, the Beijing Industry and Commerce Bureau applied a GM mode and divided its jurisdictions into a number of grid cells, where administrators were responsible for economic account ability in 2003. This improvement essentially guarantees the success of economic account supervision [17]. In the urban management field, Beijing Dong Cheng district government began to implement the "urban GM" in 2004 and established the "100 meter $\times 100$ meter GM method" [18]. This innovative management method has been popularized in many provinces of China.

Objective buffer analysis has been applied to the research on the calculation of objective deviation. The idea of "Objective buffer" comes from the critical chain management theory [19, 20]. Some scholars used buffer theory to manage the uncertainty in project. Long et al. [21] developed a fuzzy critical chain method for project scheduling under resource constraints and uncertainty. It focused on the penetration level in the project buffer and dynamically updated the schedule to provide a more accurate schedule. The current buffer monitoring mechanism has a problem of neglecting the dynamic feature of the project execution and related activity information when taking corrective actions, $\mathrm{Hu}$ et al. [22] proposed a new project schedule monitoring framework by introducing the activity index as a trigger for effective expediting to be integrated into the buffer monitoring process. Yeo et al. [23] created an enhanced critical supply chain management model for major equipment procurement to achieve better management of time uncertainty. This model did not perceive uncertainty purely as a threat, but also as an opportunity to reduce procurement cycle times. Some researches complement the buffer concept with earned value management to improve the project control process [24].

Buffer analysis in current research is always used to deal with the uncertain time of project. In the objective deviation real-time monitor model, this study extended the applicable scope to all the objectives of engineering project, and determined the objective deviation by real-time monitoring the change in objective buffer. This paper aimed to design an objective deviation real-time monitor model based on GM and objective buffer analysis. When deviation appears in the construction process, the severity of the deviation will be timely analyzed and feedback hierarchically to project managers. The structure and content of the objective deviation in real-time monitor model will be described in detail below. In section 1, the overview about the GM and buffer analysis has been introduced; section 2 introduces the grid structure of the real-time monitor model; section 3 presents the buffer analysis in deviation level calculation. In 
section 4, the principal part construction of Shenyang Olympic Tennis court is discussed as the example to illustrate the real-time monitor process in detail; section 5 gives the conclusions of the research in this paper.

\section{GM IN THE ESATBLISHMENT OF THE GRID MONITOR STRUCTURE}

Generally, the scientific level of the monitoring points' distribution and real-time data selection determine the accuracy of the project objective situation reflection and deviation real-time analysis. As indicated above, grid technology and GM have the characters of real-time, data sharing, rapid positioning and eliminate blind areas, which closely meet the requirements of the real-time monitor model. Therefore, this study applied GM for designing the realtime monitor model structure. According to the GM regulation and monitoring points' distribution requirement, the real-time monitor grid structure has been constructed in three dimensions: level, milestone and objective.

\subsection{Level Dimension}

In the level dimension, the whole working process of construction is broken down into hierarchical work packages or activities based on the analysis of the project work breakdown structure (WBS). The WBS subdivides projects into manageable units of work to be performed through the definition of various levels of hierarchy described and illustrated. The top of the hierarchy is the scope of the project. Each succeeding level in the hierarchy provides greater detail of the groupings and individual tasks to be performed [25]. Building a WBS in an engineering project can accurately determine the project scope and work procedures workload. As a special product, the construction process of a project consists of many activities, each activity having its own objectives such as cost and time limit. Therefore, in order to monitor objectives, project WBS needs to be built first, then the objectives of individual activity have to be controlled and finally integrated into the overall objective monitor system. In addition, the project WBS can also avoid the chaotic relationship of activities within the project organization structure, which may lead to some overlooked work. In this paper, the principal part construction of the Shenyang Olympic tennis court was selected as an example to illustrate the establishment process of an engineering project objective deviation real-time monitor model. Fig. (1) shows the WBS of this project.

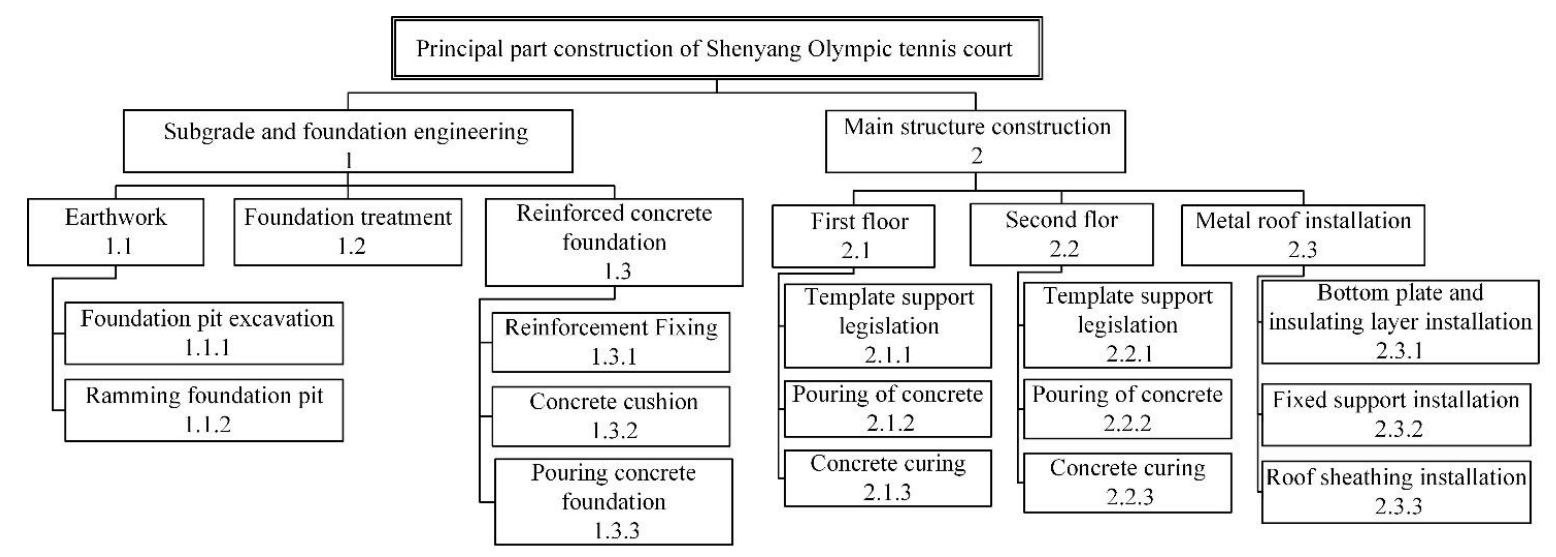

Fig. (1). The WBS of Shenyang Olympic tennis court principal part construction.

\subsection{Milestone Dimension}

Milestone can be defined as the completion of an important activity [26]. In engineering project management, the word "milestone" describes a certain point in time at which an activity is to be completed. The milestone management mode is typically a result-oriented management mode, judging whether a length of project process is reasonable through the completion of the milestone [27]. Behavior-oriented management mode is more detailed and complex, the resultoriented milestone management mode is more applicable to engineering project management compared with the totally behavior-oriented management mode [28]. In order to carry out the real-time monitoring of engineering project better, this study arranged activities at every level in accordance with the work orders and then marked the monitoring milestones based on WBS structure and the organization plan of the project. As the smallest time unit, milestone simulates real-time with intensive time node. It can not only meet the timeline requirements of project monitoring, but also improve the feasibility and save the management resources. Fig. (2) shows the Gantt chart of the Shenyang Olympic tennis court principal part construction, and the grid structure in level and milestone dimension is shown in Fig. (3). 


\begin{tabular}{|c|c|c|c|c|c|c|c|c|c|c|c|c|c|c|}
\hline \multirow{2}{*}{ ID } & \multirow{2}{*}{ Activity } & \multirow{2}{*}{ Start time } & \multirow{2}{*}{$\begin{array}{c}\text { Completion } \\
\text { Time }\end{array}$} & \multirow{2}{*}{ Duration } & \multicolumn{5}{|c|}{2007} & \multicolumn{5}{|c|}{2008} \\
\hline & & & & & Aug & Sept & Oct & Vov & Dec & Jan & Feb & Mar & June & July \\
\hline 1 & 1.1 .1 & $2007-7-20$ & $2007 / 8 / 8$ & $20 \mathrm{~d}$ & & & & & & & & & & \\
\hline 2 & 1.1 .2 & $2007 / 8 / 5$ & $2007 / 8 / 13$ & $9 \mathrm{~d}$ & 5 & & & & & & & & & \\
\hline 3 & 1.2 & $2007 / 8 / 14$ & $2007 / 8 / 25$ & $12 \mathrm{~d}$ & & & & & & & & & & \\
\hline 4 & 1.3 .1 & $2007 / 8 / 26$ & $2007 / 9 / 12$ & $18 \mathrm{~d}$ & & & & & & & & & & \\
\hline 5 & 1.3 .2 & $2007 / 9 / 5$ & $2007 / 9 / 20$ & $16 \mathrm{~d}$ & & & & & & & & & & \\
\hline 6 & 1.3 .3 & $2007 / 9 / 21$ & $2007 / 10 / 2$ & $12 \mathrm{~d}$ & & & & & & & & & & \\
\hline 7 & 2.1 .1 & $2007 / 10 / 3$ & $2007 / 10 / 28$ & $26 \mathrm{~d}$ & & & & & & & & & & \\
\hline 8 & 2.1 .2 & $2007 / 10 / 29$ & $2007 / 11 / 15$ & $18 \mathrm{~d}$ & & & & & & & & & & \\
\hline 9 & 2.1 .3 & $2007 / 11 / 1$ & $2007 / 12 / 1$ & $31 d$ & & & & & & & & & & \\
\hline 10 & 2.2 .1 & $2007 / 12 / 2$ & $2007 / 12 / 27$ & $26 \mathrm{~d}$ & & & & & & & & & & \\
\hline 11 & 2.2 .2 & $2007 / 12 / 28$ & $2008 / 1 / 14$ & $18 \mathrm{~d}$ & & & & & & & & & & \\
\hline 12 & 2.2 .3 & $2008 / 1 / 5$ & $2008 / 2 / 4$ & $31 \mathrm{~d}$ & & & & & & & & & & \\
\hline 13 & \begin{tabular}{l|} 
Spring \\
Festival \\
\end{tabular} & $2008 / 2 / 5$ & $2008 / 2 / 24$ & $20 \mathrm{~d}$ & & & & & & & & & & \\
\hline 14 & 2.3 .1 & $2008 / 2 / 25$ & $2008 / 4 / 2$ & $38 \mathrm{~d}$ & & & & & & & & & & \\
\hline 15 & 2.3 .2 & $2008 / 4 / 3$ & $2008 / 5 / 1$ & $29 \mathrm{~d}$ & & & & & & & & & & \\
\hline 16 & 2.3 .3 & $2008 / 5 / 2$ & $2008 / 5 / 31$ & $30 \mathrm{~d}$ & & & & & & & & & & \\
\hline
\end{tabular}

Fig. (2). Gantt chart of Shenyang Olympic tennis court principal part construction.

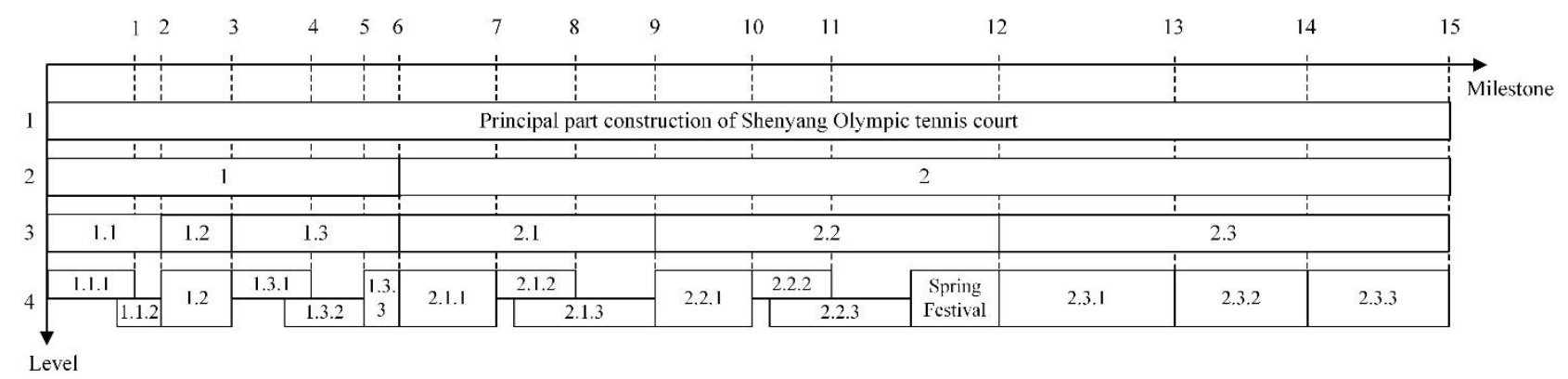

Fig. (3). The grid structure in level and milestone dimension.

\subsection{Objective Dimension}

The objective refers to the main element needs to be managed during the construction process [29]. Management by objectives (MBO) was put forward by American management guru Peter Drucker in 1954; it is a method that can improve the productivity and efficiency of an organization based on formulated objectives. Each project must commit to productivity objectives and self-efficacy in improving productivity, while improving the work during the process of achieving objectives [30]. Recently, multi-objective control and objective quantification administration have become a main focus of project management [31], therefore, this paper we considered the project objectives as one of the gridding dimensions. Through intensive study, it was found that depending on management characteristic, the main project objectives in an engineering project can be divided into two types. The first kind is named March Objective (MO), classified as quantitative objective at the project progresses, such as cost objective, schedule objective, material objective and so on [32]. The second kind of objective is Fixed Objective (FO), defined as management standards at a 
certain stage due to the limitations of industry standards and relevant policy, such as safety objective, quality objective, environment objective and so on. This classification has a great influence on the deviation calculation method selection, discussed in the section below.

With the addition of the objective dimension, the completed real-time monitor grid is shown in Fig. (4). Grid cell is the smallest minimum control node of the grid structure.

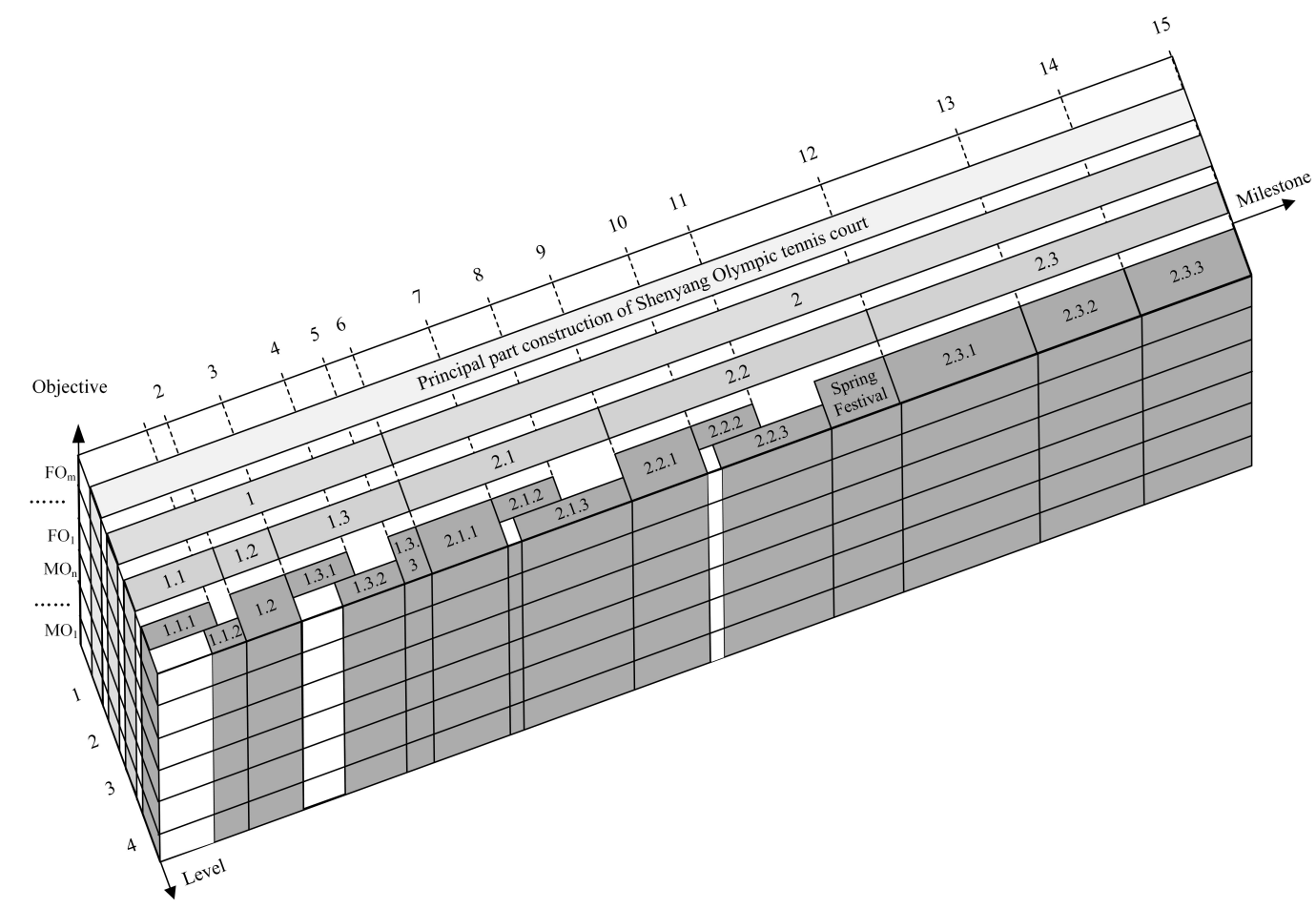

Fig. (4). The completed real-time monitor grid structure.

\section{BUFFER ANALYSIS IN DEVIATION LEVEL CALCULATION}

The algorithms such as evolutionary algorithms, genetic algorithms, fuzzy comprehensive evaluation and BP neural network algorithms have been applied to the study on various project life cycle control topics. These algorithms are all frequent and popular due to the possibility of optimization and finding good solutions [33]. This paper is devoted to calculate the actual deviation with planned objective states, so that corrective actions can be taken to meet the project plan. On the basis of grid structure, buffer analysis was proposed after taking the mentioned project control algorithms into consideration. In critical chain management, a project buffer at the end of the critical path is the difference between the due date and the expected completion time. The buffer will absorb the uncertainty in the project and reduce the possibility of delay. Inspired by this method, this paper attempts to assess project deviation level in time by observing the change in objective buffer consumption (BC). The BC is defined as the D-value of actual objective value and expected value.

Instead of studying single objective control or multi-objective interaction problems, this paper attempts to make the buffer analysis method suitable for most engineering project objectives. As mentioned above, according to the characteristics of the buffer analysis requirements, the main project objectives in engineering projects were divided into two types: MO and FO, the suitable BC calculation method was assigned accordingly.

\subsection{BC Calculation and Deviation Level of MO}

\subsubsection{Buffer Preset of MO}

In MO, if objective deviation appears in one grid cell, it means that objective BC appeared, and it will directly affects the objective buffer quantity of all the subsequent grid cells. Taking schedule objective as an example, if one activity is delayed, in order to ensure that the project is completed on schedule, the time limit of subsequent activities 
will be reduced. In this situation, two kinds of buffer in every MO are added. The stage buffer (SB) is added at the end of project stages of each WBS level (stage means the sum of the subsidiary grids that branched from one parent grid at the upper level), which will absorb the deviation at the first stage and reduce the influence at the next stage. Meanwhile, the project total buffer (PB) is added at the end of the project, which reflects the difference between the critical completion value and the expected completion value and absorbs the deviation in the whole project. Fig. (5) gives an example of buffers added in one objective of MO.

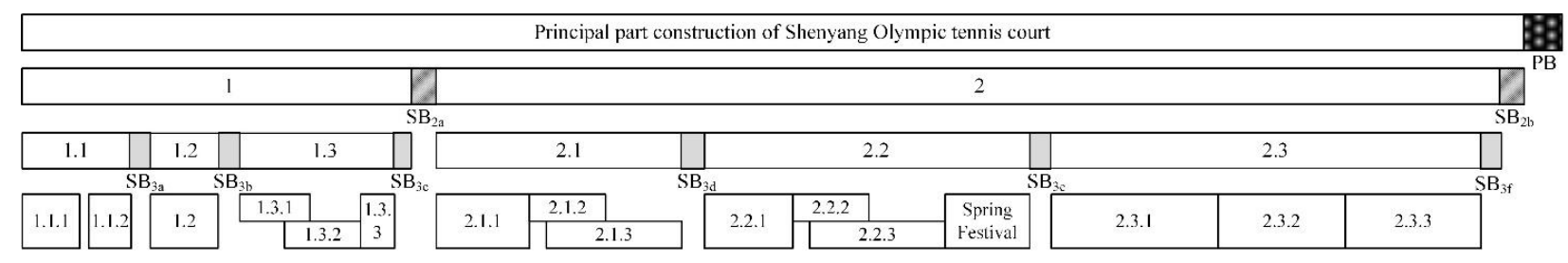

Fig. (5). Example of buffers added in one objective of MO.

\subsubsection{BC and Deviation Level Measurement of MO}

In accordance with the project contract and construction program, SB and PB in every objective have been predesigned in the project planning phase. The amount of SB is not same for all stages, some even equal zero. During construction, the objective buffer amount of subsequent grid cells will dynamically change for the consumption of buffers in previous grid cells. Therefore, when the project reaches a new grid cell, SB and PB should be dynamically adjusted:

Based on the principle of minimizing the impact to subsequent grid:

- If SB of one stage does not used up, the remaining is added to PB.

- If the deviation at one stage is bigger than $\mathrm{SB}$, the lack of $\mathrm{BC}$ is deducted from $\mathrm{PB}, \mathrm{SB}$ in upper level, and $\mathrm{SB}$ of subsequent grid cells; the priority is: $\mathrm{PB} \rightarrow \mathrm{SB}$ in upper level $\rightarrow \mathrm{SB}$ in subsequent grids $\rightarrow \mathrm{SB}$ in other root grids (in Fig. (5), if $\mathrm{SB}_{3 \mathrm{a}}$ used up, the deduct sequence is $\left.\mathrm{PB} \rightarrow \mathrm{SB}_{2 \mathrm{a}} \rightarrow \mathrm{SB}_{3 \mathrm{~b}} \backslash \mathrm{SB}_{3 \mathrm{c}} \rightarrow \mathrm{SB}_{2 \mathrm{~b}} \rightarrow \mathrm{SB}_{3 \mathrm{~d}} \backslash \mathrm{SB}_{3 \mathrm{e}} \backslash \mathrm{SB}_{3 \mathrm{f}}\right)$.

In construction, when a project reaches one milestone, we can identify the severity of the impact of deviation on the overall project by comparing real-time BC (the D-value of actual objective value and expected value) of this grid cell with the corresponding preset buffer. Therefore, the objective deviation severity can be divided into 6 levels. Assuming that $\mathrm{BC}_{\mathrm{i}}$ is $\mathrm{BC}$ at milestone $\mathrm{i}$, which belongs to stage $\mathrm{j}$ :

- No deviation: $\mathrm{BC}_{\mathrm{i}} \leq 0, \mathrm{SB}_{\mathrm{j}}$ has not yet been consumed. It indicates that this objective is working well and completely in accordance with the plan.

- Deviation I: $0 \leq \mathrm{BC}_{\mathrm{i}} \leq \mathrm{SB}_{\mathrm{j}}$, only $\mathrm{SB}_{\mathrm{j}}$ has been consumed. It indicates that deviation exists in this grid cell, but will not affect plan of other grids.

- Deviation II: $\mathrm{SB}_{\mathrm{j}}<\mathrm{BC}_{\mathrm{i}} \leq \mathrm{SB}_{\mathrm{j}}+\mathrm{PB}$, in this situation, deviation exists and will consume $\mathrm{PB}$, but will not affect the plan of other grids and make the project exceed the critical completion value.

- Deviation III: $\mathrm{SB}_{\mathrm{j}}+\mathrm{PB}<\mathrm{BC}_{\mathrm{i}} \leq \mathrm{PB}+\sum_{\mathrm{a}=1}^{\mathrm{k}} \mathrm{SB}_{\mathrm{a}}$, where $\mathrm{k}$ is the number of $\mathrm{SB}$ contained in the roof grid containing $\mathrm{SB}_{\mathrm{i}}$. In this situation, deviation will consume $\mathrm{PB}$ and $\mathrm{SB}$ within the same roof grid, but will not affect the plan of other roof grids and make the project exceed the critical completion value if subsequent activities stick to the objective plan.

- Deviation IV: $\mathrm{PB}+\sum_{\mathrm{a}=1}^{\mathrm{k}} \mathrm{SB}_{\mathrm{a}}<\mathrm{BC}_{\mathrm{i}} \leq \mathrm{PB}+\sum_{\mathrm{a}=1}^{\mathrm{q}} \mathrm{SB}_{\mathrm{a}}$, where $\mathrm{q}$ is the number of $\mathrm{SB}$ contained in the whole project. It indicates that the deviation has affected the plan of subsequent activities, but the project may not exceed the critical completion value if the buffer in subsequent activities is deducted.

- Deviation $\mathrm{V}: \mathrm{PB}+\sum_{\mathrm{a}=1}^{\mathrm{q}} \mathrm{SB}_{\mathrm{a}}<\mathrm{BC}$, objective deviation has exceeded all the buffers, even if activities in the subsequent grid cells stick to the plan, the objective cannot be corrected and will certainly exceed the contract limit. 


\subsection{BC Calculation and Deviation Level of FO}

As indicated above, the real situation of FO is mainly reflected in the periodic experiment or test results, such as regular environmental monitoring, quality acceptance, etc. instead of obtaining objective deviation through measuring the actual time or cost. These evaluations or tests usually adopt the sampling tests method and the result is mostly expressed in a set of fuzzy labels (excellent, good, or bad), which produce strong uncertainty. To catch the dynamic BC through the milestone test result, an algorithm in the fuzzy decision tree is used for reference.

Fuzzy decision tree combines symbolic tree structures with approximate reasoning offered by fuzzy representation, and has been proven to be a strong classifier and predictor of real-world decision application. In recent years, the increasing popularity of the use of hierarchically organized fuzzy trees has led to the problem of data comparison when it takes a tree structure form, which is as FO buffer analysis needs.

\subsubsection{FO Fuzzy Grid Relationship Definition}

The grid structure in Fig. (3) is similar to a tree structure, it is developed by the project WBS. The grid cell on the bottom layer are leaves of a tree (nodes without successors), named as leaf grid cells and indicate basic units (single milestone test results in FO monitor). The rest of the grids are called superior grid cells.

As mentioned above, the status of the FO milestone test is usually expressed in levels (excellent, good, or bad). In such cases, the description of milestone status takes the form of a fuzzy grid structure $G(X, U)$. Each grid cell $x \in X$ represents the objective status at a certain milestone, and $U$ is a set of fuzzy relations. Therefore, the objective status of each milestone can be characterized by a set of fuzzy labels $L=\left\{1_{a}, 1_{b}, \cdots, 1_{m}\right\}$, where $1_{a}, 1_{b}, \cdots, 1_{m}$ represent status of FO milestone test.

Due to the fuzzy character of the objective status in each milestone, these grid cells $x \in X$ with fuzzy labels $L$ should be characterized by a membership function $\mu_{\mathrm{L}}(\mathrm{x})$. The membership function $\mu_{\mathrm{L}}(\mathrm{x})$ represents the degree of membership of the element $\mathrm{x}$ in a fuzzy label L. Membership function should be determined according to the actual project and experience.

In order to confirm the value of a membership function $\mu_{L}(x)$ of a grid cell $x_{k}$ at the label $1_{a}$, membership functions are written in the form of a membership matrix of relations:

$$
\mu(x, 1)=\left[\begin{array}{cccc}
\frac{\mu_{x 1}}{1_{a}} & \frac{\mu_{x 1}}{1_{b}} & \ldots & \frac{\mu_{x 1}}{1_{m}} \\
\frac{\mu_{x 2}}{1_{a}} & \frac{\mu_{x 2}}{1_{b}} & \ldots & \frac{\mu_{x 2}}{1_{m}} \\
\vdots & \vdots & \vdots & \vdots \\
\frac{\mu_{x n}}{1_{a}} & \frac{\mu_{x n}}{1_{b}} & \cdots & \frac{\mu_{x n}}{1_{m}}
\end{array}\right]
$$

\subsubsection{Buffer Preset of FO}

After defining the fuzzy relationship of the FO grid, the FO buffer and real-time BC can be calculated. Earlier in the paper, two kinds of buffer were added in MO; for FO, there is only one kind of buffer: showing the distance between the ideal and critical situation (DB). Therefore, in order to set a reasonable DB, the ideal situation and critical situation should be confirmed before beginning construction, that is, the ideal objective status $\mathrm{X}_{\mathrm{i}}$ and critical objective status $\mathrm{x}_{\mathrm{c}}$ of each leaf grid cell should be determined.

Distance between $\mathrm{x}_{\mathrm{i}}$ and $\mathrm{x}_{\mathrm{c}}$ in one leaf grid cell is defined as follow:

$$
\mathrm{D}_{\mathrm{x}_{\mathrm{i}}-\mathrm{x}_{\mathrm{c}}}=\sum_{\mathrm{z}=1}^{\mathrm{m}}\left|\mu\left(\mathrm{x}_{\mathrm{i}}, 1_{\mathrm{z}}\right)-\mu\left(\mathrm{x}_{\mathrm{c}}, \mathrm{l}_{\mathrm{z}}\right)\right| \cdot \mathrm{K}
$$

Where $\mu\left(X_{i}, l_{z}\right)$ and $\mu\left(X_{c}, l_{z}\right)$ are membership matrices of relations between the ideal situation grid and the critical situation grid, $\mathrm{m}$ is the number of elements in fuzzy labels $\mathrm{L}$, and $\mathrm{K}$ is the weighting coefficient added in each grid cell. 
For the significance of each leaf grid cell to the overall project FO is different, the weighting coefficient of a superior grid cell P can be defined as follow:

$$
\mathrm{K}_{\mathrm{p}}=\sum_{\mathrm{z}=1}^{\mathrm{S}} \mathrm{K}_{\mathrm{z}}
$$

Where $\mathrm{S}$ is the number of successors of the superior grid cell $\mathrm{P}$.

According to the definition, DB should be the sum of $\mathrm{D}_{\mathrm{xi-xc}}$ in all the leaf grid cells. But when preset DB in each leaf grid cell, the $\mathrm{D}_{\mathrm{xixc}}$ in the following grid cell will not affect the DB in the previous grid cell, therefore, the DB in milestone dimension is a process of accumulation. $\mathrm{DB}$ of leaf grid cell $\mathrm{Q}$ is the sum of $\mathrm{D}_{\mathrm{xi}-\mathrm{xc}}$ in previous leaf grid cell.

$$
\mathrm{DB}_{\mathrm{Q}}=\sum_{\mathrm{z}=1}^{\mathrm{w}} \mathrm{D}_{\mathrm{x}_{\mathrm{i} z}-\mathrm{x}_{\mathrm{cz}}}
$$

Where $\mathrm{w}$ is the number of grid cells finished before leaf grid cell Q. With the advancement of the engineering project, the DB also increases accordingly.

\subsubsection{BC and Deviation Level Measurement of FO}

Similar to MO, DB calculation and preset take place in the project planning phase. In order to monitor the FO realtime deviation since commencement, the $\mathrm{BC}$ of $\mathrm{DB}$ should be timely measured when a project reaches a milestone.

The $\mathrm{BC}$ has been defined as the $\mathrm{D}$-value of actual objective value and expected value in this paper. Therefore, in the $\mathrm{BC}$ measurement of $\mathrm{FO}$, the distance between $\mathrm{x}_{\mathrm{i}}$ and actual objective status $\mathrm{x}_{\mathrm{a}}$ in one leaf grid cell should be calculated first, similar to Equation (2):

$$
\mathrm{D}_{\mathrm{x}_{\mathrm{i}}-\mathrm{x}_{\mathrm{a}}}=\sum_{\mathrm{z}=1}^{\mathrm{m}}\left|\mu\left(\mathrm{x}_{\mathrm{i}}, \mathrm{l}_{\mathrm{z}}\right)-\mu\left(\mathrm{x}_{\mathrm{a}}, \mathrm{l}_{\mathrm{z}}\right)\right| \cdot \mathrm{K}
$$

Where $\mu\left(X_{a}, l_{z}\right)$ is a membership matric of relations of the actual situation grid $a$, and $m$ is the number of elements in fuzzy labels $\mathrm{L}$.

As with DB measurement, $\mathrm{BC}$ should be the sum of $\mathrm{D}_{\mathrm{xi}-\mathrm{xa}}$ in all the leaf grid cells. When $\mathrm{BC}$ was measured in one grid cell, the $\mathrm{D}_{\mathrm{xi-xc}}$ in the following grid cells was not observed. During the progression of the engineering project, the $\mathrm{BC}$ is also considered a process of accumulation. $\mathrm{BC}$ of leaf grid cell $\mathrm{Q}$ is the sum of $\mathrm{D}_{\mathrm{xi} \times \mathrm{xa}}$ in the previous leaf grid cell.

$$
\mathrm{BC}_{\mathrm{Q}}=\sum_{\mathrm{z}=1}^{\mathrm{w}} \mathrm{D}_{\mathrm{x}_{\mathrm{iz}}-\mathrm{x}_{\mathrm{cz}}}
$$

Where $\mathrm{w}$ is the number of grid cells finished before leaf grid cell $\mathrm{Q}$.

The result of the $\mathrm{BC}$ is a non-fuzzy distance between actual objective status and ideal objective status. The objective deviation information can be easily acquired by comparing $\mathrm{BC}_{\mathrm{Q}}$ with $\mathrm{DB}_{\mathrm{Q}}$. An additional fuzzification calculation should be done to obtain a clear deviation level.

$\mathrm{BC}$ needs to be normalized to comply with $\mathrm{DB}$. The ideal situation $(\mathrm{BC}=0)$ is ascribed to a real value $\mathrm{B}_{\mathrm{i}}$, and the critical situation, which represents a poorly acceptable status $(B C=D B)$, is ascribed to a real value $B_{c}$. Normalized $B C$ $\left(B_{a}\right)$ is obtained by the following transformation:

$$
\mathrm{B}_{\mathrm{a}}=\mathrm{B}_{\mathrm{i}}-\frac{\mathrm{B}_{\mathrm{i}}-\mathrm{B}_{\mathrm{c}}}{\mathrm{DB}} \cdot \mathrm{BC} \quad(0 \leq \mathrm{BC} \leq \mathrm{DB})
$$

The deviation level can be calculated by substituting the normalized $\mathrm{BC}$ into the membership functions $\mu \mathrm{L}(\mathrm{x})$ used above according to the principle of maximum membership degree. 


\section{EXAMPLE APPLICATION}

The principal part construction of Shenyang Olympic Tennis court was selected as the example to illustrate the realtime monitor process in detail. The project was completed in the end of year 2007. Because this project belongs to the Olympic demonstration engineering project, the detailed construction process records data that reflect some objectives' stated during construction. Therefore, we chose this project as a calculation example. For space limitations, only schedule and quality objective data in the subgrade and foundation engineering stage have been discussed in this paper. Grid monitor structure should be built before the start of a project. The building stages and the completed grid were mentioned earlier (Fig. 4).

\subsection{Buffer Analysis of Schedule Objective}

Referring to the progress plan (Fig. 3) and workforce capability of Shenyang Olympic Tennis court, the preset buffers of the project are shown in Table 1. The actual progress of subgrade and foundation engineering stage is shown in Table 2. According to the data in Tables $\mathbf{1}$ and 2, the deviation level measurement process is shown in Table $\mathbf{3}$.

Table1. Preset schedule buffers of Shenyang Olympic Tennis court principal part construction.

\begin{tabular}{|c|c|c|c|c|c|c|c|c|c|c|c|c|c|c|c|c|c|c|}
\hline Grid cell & 1.1 .1 & \begin{tabular}{|l|}
1.1 .2 \\
\end{tabular} & 1.2 & 1.3 .1 & 1.3 .2 & 1.3 .3 & 1 & 2.1 .1 & 2.1 .2 & 2.1 .3 & 2.2 .1 & 2.2 .2 & 2.2 .3 & 2.3 .1 & 2.3 .2 & 2.3 .3 & 2 & \\
\hline planed value (day) & 16 & 7 & 11 & 18 & 13 & 10 & & 23 & 18 & 26 & 23 & 18 & 26 & 34 & 25 & 26 & & \\
\hline SB (day) & 2 & & 0 & & 3 & & 3 & & 8 & & & 8 & & & 8 & & 9 & \\
\hline PB (day) & & & & & & & & & & & & & & & & & & 20 \\
\hline
\end{tabular}

Table 2. Actual progress of subgrade and foundation engineering stage.

\begin{tabular}{|c|c|c|c|c|c|}
\hline Grid cell & 1.1 .1 & 1.1 .2 & 1.2 & 1.3 .1 & 1.3 .2 \\
\hline Actual value (day) & 20 & 5 & 1.3 .3 & 22 & 14 \\
\hline
\end{tabular}

Table 3. Deviation level measurement process.

\begin{tabular}{|c|c|c|c|c|}
\hline Grid cell & Buffer analy & sis & Deviation level & Remark \\
\hline 1.1 .1 & $20-16=4$ & \multirow{2}{*}{$\mathrm{BC}_{1.1}=2=\mathrm{SB}_{1.1}$} & \multirow{2}{*}{ Deviation I } & \multirow{2}{*}{--} \\
\hline 1.1 .2 & $5-7=-2$ & & & \\
\hline 1.2 & $12-11=1$ & $\begin{array}{c}\mathrm{BC}_{1.2}=1 \\
\mathrm{SB}_{1.2}<\mathrm{BC}_{1.2}<\mathrm{SB}_{1.2}+\mathrm{PB}\end{array}$ & Deviation II & $\mathrm{PB}^{\prime}=20-1=19$ \\
\hline 1.3 .1 & $22-18=4$ (Non-critical activities) & \multirow{3}{*}{$\begin{array}{c}\mathrm{BC}_{1.3}=4 \\
\mathrm{SB}_{1.3}<4<\mathrm{SB}_{1.3}+\mathrm{PB}\end{array}$} & \multirow{3}{*}{ Deviation II } & \multirow{3}{*}{$\begin{array}{c}\mathrm{PB} "=19+(3-4)=18 \\
\text { Stage } 1 \text { over, the rest } \mathrm{SB} \text { added to } \mathrm{PB} \\
\mathrm{PB} "=\mathrm{PB} "+\mathrm{SB}_{1}=18+3=21\end{array}$} \\
\hline 1.3.2 & $14-13=1$ & & & \\
\hline 1.3 .3 & $13-10=3$ & & & \\
\hline
\end{tabular}

In grid cell 1.1, $\mathrm{BC}_{1.1 .1}$ is 4 days, $\mathrm{BC}_{1.1 .2}$ is -2 days. Because of the delay of work 1.1.1, the starting time of work 1.1.2 delayed for 4 days, as the work 1.1.2 fulfilled ahead of schedule, while, the actual BC of grid 1.1 is two days, which can be absorbed by the $\mathrm{SB}_{1.1}$. This situation accords with the Deviation I

In grid cell 1.2, $\mathrm{BC}_{1.2}$ is 1 day, as there is no $\mathrm{SB}$ in this grid cell; one day in $\mathrm{PB}$ must be consumed to absorb the delay. This situation accords with the Deviation II.

In grid cell 1.3, work 1.3.1 delayed for 4 days. As can be seen in Fig. (3), that work 1.3.1 represents non-critical activities, there is free time between work 1.3.1 and 1.3.3, therefore, this delay without any loss of buffer. $\mathrm{BC}_{1.3 .2}$ is 1 day, $\mathrm{BC}_{1.3 .3}$ is 3 days, so $\mathrm{BC}_{1.3}$ is 4 days, which is more than $\mathrm{SB}_{1.3}$, This situation accords with the Deviation II.

In the actual situation, because of lack of timely objective monitoring applied, delay appeared in the work 1.2, and becomes more increases over-time serious along with the advancement of engineering. The actual completion time was three months than more the planned time. If the real-time monitor method is used in this project, the schedule objective deviation state would reflected to project manager timely, and corrective measures can be adopted to avoid delay.

\subsection{Buffer Analysis of Quality Objective}

In this project, quality evaluation at each milestone is characterized by five levels (Table 4):

The values of the possible level of leaf grid cell represent a set of fuzzy labels L $\{$ I, II, III, IV, V\}. 
Table 4. Quality evaluation levels.

\begin{tabular}{|c|c|c|}
\hline Level & Description & Value \\
\hline I & Perfect & 100 \\
\hline II & Good & 60 \\
\hline III & Normal & 50 \\
\hline IV & Poor & 0 \\
\hline V & Very poor & 55 \\
\hline
\end{tabular}

According to the experience data statistics of similar projects and expert analysis, cosinusoid membership functions were considered to be the most suitable for this project.

$$
\mu_{1}(\mathrm{x})=\frac{1}{2} \cdot \cos \left(\pi \cdot \frac{\mathrm{x}-1}{100}\right)+\frac{1}{2}
$$

Substituting the level value into membership function, the membership matrix can be rewritten as follow:

$$
\mu(\mathrm{x}, \mathrm{l})=\text { III }\left|\begin{array}{ccccc}
\frac{1}{\mathrm{I}} & \frac{0.905}{\mathrm{II}} & \frac{0.727}{\mathrm{III}} & \frac{0.5}{\mathrm{IV}} & \frac{0}{\mathrm{~V}} \\
\frac{0.905}{\mathrm{I}} & \frac{1}{\mathrm{II}} & \frac{0.946}{\mathrm{III}} & \frac{0.794}{\mathrm{IV}} & \frac{0.095}{\mathrm{~V}} \\
\frac{0.727}{\mathrm{I}} & \frac{0.946}{\mathrm{II}} & \frac{1}{\mathrm{II}} & \frac{0.946}{\mathrm{IV}} & \frac{0.273}{\mathrm{~V}} \\
\frac{0.5}{\mathrm{I}} & \frac{0.794}{\mathrm{II}} & \frac{0.946}{\mathrm{III}} & \frac{1}{\mathrm{IV}} & \frac{0.5}{\mathrm{~V}} \\
\frac{0}{\mathrm{I}} & \frac{0.095}{\mathrm{II}} & \frac{0.273}{\mathrm{III}} & \frac{0.5}{\mathrm{IV}} & \frac{1}{\mathrm{~V}}
\end{array}\right|
$$

Table 5 shows the DB preset in quality objective. Ideal objective status $x_{i}$ and critical objective status $x_{c}$ of each leaf grid cell were set in the design document, which is marked by fuzzy values $\mathbf{L}\{$ I, II, III, IV, V\}. The normalized weighted coefficient $\mathrm{K}$ is in parentheses. The DB was calculated from $\mathrm{x}_{\mathrm{i}}$ and $\mathrm{x}_{\mathrm{c}}$ according to the equations (2), (3), (4).

\begin{tabular}{|c|c|c|c|c|c|c|c|c|c|c|c|c|c|c|c|}
\hline \multirow{3}{*}{ Grid cell(K) } & \multicolumn{6}{|c|}{$1(0.50)$} & \multicolumn{9}{|c|}{$2(0.50)$} \\
\hline & \multicolumn{2}{|c|}{$1.1(0.25)$} & \multirow{2}{*}{$\begin{array}{c}1.2(0.30) \\
1.2 \\
(1) \\
\end{array}$} & \multicolumn{3}{|c|}{$1.3(0.45)$} & \multicolumn{3}{|c|}{$2.1(0.32)$} & \multicolumn{3}{|c|}{$2.2(0.28)$} & \multicolumn{3}{|c|}{$2.3(0.40)$} \\
\hline & $\begin{array}{l}1.1 .1 \\
(0.74)\end{array}$ & \begin{tabular}{|c|}
1.1 .2 \\
$(0.26)$ \\
\end{tabular} & & \begin{tabular}{|c|}
1.3 .1 \\
$(0.30)$ \\
\end{tabular} & \begin{tabular}{|c|}
1.3 .2 \\
$(0.26)$ \\
\end{tabular} & \begin{tabular}{|c|}
1.3 .3 \\
$(0.44)$ \\
\end{tabular} & $\begin{array}{c}2.1 .1 \\
(0.28) \\
\end{array}$ & \begin{tabular}{|c|}
2.1 .2 \\
$(0.49)$ \\
\end{tabular} & $\begin{array}{c}2.1 .3 \\
(0.23) \\
\end{array}$ & $\begin{array}{c}2.2 .1 \\
(0.28) \\
\end{array}$ & $\begin{array}{c}2.2 .2 \\
(0.49) \\
\end{array}$ & \begin{tabular}{|c|}
2.2 .3 \\
$(0.23)$ \\
\end{tabular} & \begin{tabular}{|c|}
2.3 .1 \\
$(0.30)$ \\
\end{tabular} & \begin{tabular}{|c|}
2.3 .2 \\
$(0.30)$ \\
\end{tabular} & $\begin{array}{r}2.3 .3 \\
(0.40) \\
\end{array}$ \\
\hline$x_{i}$ & I & I & I & I & I & I & I & I & I & I & I & I & I & I & I \\
\hline $\mathrm{X}_{\mathrm{c}}$ & IV & II & III & III & III & II & IV & III & III & IV & III & III & III & III & II \\
\hline DB & 11.67 & 12.13 & 21.16 & 25.23 & 28.75 & 30.14 & 35.79 & 40.51 & 42.73 & 47.67 & 51.80 & 53.74 & 57.36 & 60.97 & 62.09 \\
\hline
\end{tabular}

Table 5. The DB calculation result preset in quality objective.

Table 6 shows the real-time evaluation statistic that represents the actual quality status $\mathrm{x}_{\mathrm{a}}$ in some milestones.

\begin{tabular}{|c|c|c|c|c|c|c|c|c|c|c|c|c|c|c|c|c|}
\hline \multirow{3}{*}{\multicolumn{2}{|c|}{ Grid cell(K) }} & \multicolumn{6}{|c|}{$1(0.50)$} & \multicolumn{9}{|c|}{$2(0.50)$} \\
\hline & & \multicolumn{2}{|c|}{$1.1(0.25)$} & \multirow{2}{*}{$\begin{array}{c}1.2(0.30) \\
1.2 \\
(1)\end{array}$} & \multicolumn{3}{|c|}{$1.3(0.45)$} & \multicolumn{3}{|c|}{$2.1(0.32)$} & \multicolumn{3}{|c|}{$2.2(0.28)$} & \multicolumn{3}{|c|}{$2.3(0.40)$} \\
\hline & & $\begin{array}{c}1.1 .1 \\
(0.74)\end{array}$ & $\begin{array}{c}1.1 .2 \\
(0.26)\end{array}$ & & $\begin{array}{c}1.3 .1 \\
(0.30)\end{array}$ & $\begin{array}{c}1.3 .2 \\
(0.26)\end{array}$ & $\begin{array}{l}1.3 .3 \\
(0.44)\end{array}$ & $\begin{array}{l}2.1 .1 \\
(0.28)\end{array}$ & $\begin{array}{l}2.1 .2 \\
(0.49)\end{array}$ & $\begin{array}{c}2.1 .3 \\
(0.23)\end{array}$ & $\begin{array}{l}2.2 .1 \\
(0.28)\end{array}$ & $\begin{array}{c}2.2 .2 \\
(0.49)\end{array}$ & $\begin{array}{c}2.2 .3 \\
(0.23)\end{array}$ & $\begin{array}{l}2.3 .1 \\
(0.30)\end{array}$ & \begin{tabular}{|c|}
2.3 .2 \\
$(0.30)$
\end{tabular} & \begin{tabular}{|c|}
2.3 .3 \\
$(0.40)$
\end{tabular} \\
\hline \multirow{6}{*}{ Milestone } & 1.1 .1 & III & & & & & & & & & & & & & & \\
\hline & 1.1 .2 & III & III & & & & & & & & & & & & & \\
\hline & 1.2 & II & II & I & & & & & & & & & & & & \\
\hline & 1.3 .1 & II & II & I & III & & & & & & & & & & & \\
\hline & 1.3 .2 & II & II & I & II & II & & & & & & & & & & \\
\hline & 1.3 .3 & II & II & I & II & I & II & & & & & & & & & \\
\hline
\end{tabular}

Table 6. The real-time quality evaluation statistic of subgrade and foundation engineering stage.

As shown in Table 7, the BC and normalized BC have been calculated from statistics in Table 6 according to the equations (5), (6), (7). As the quality evaluation result of grid cell 1.1.2 was below the critical objective status, the symbol " $\varnothing "$ " was used to represent this situation which is beyond the scope of BC calculation. It means that the quality 
in this grid cell is lower than the minimum permitted. Immediate rectification measures are needed to ensure that the quality of this grid cell stays above of the critical objective status.

Table 7. BC and normalized BC of subgrade and foundation engineering stage.

\begin{tabular}{|c|c|c|c|c|c|c|c|c|c|c|c|c|c|c|c|}
\hline \multirow[t]{3}{*}{ Grid cell(K) } & \multicolumn{6}{|c|}{$1(0.50)$} & \multicolumn{9}{|c|}{$2(0.50)$} \\
\hline & \multicolumn{2}{|c|}{$1.1(0.25)$} & $1.2(0.30)$ & \multicolumn{3}{|c|}{$1.3(0.45)$} & \multicolumn{3}{|c|}{$2.1(0.32)$} & \multicolumn{3}{|c|}{$2.2(0.28)$} & \multicolumn{3}{|c|}{$2.3(0.40)$} \\
\hline & \begin{tabular}{|l|}
1.1 .1 \\
$(0.74)$
\end{tabular} & $\begin{array}{l}1.1 .2 \\
(0.26)\end{array}$ & $\begin{array}{l}1.2 \\
\text { (1) }\end{array}$ & $\begin{array}{l}1.3 .1 \\
(0.30)\end{array}$ & $\begin{array}{l}1.3 .2 \\
(0.26)\end{array}$ & $\begin{array}{c}1.3 .3 \\
(0.44)\end{array}$ & $\begin{array}{l}2.1 .1 \\
(0.28)\end{array}$ & $\begin{array}{c}2.1 .2 \\
(0.49)\end{array}$ & $\begin{array}{l}2.1 .3 \\
(0.23)\end{array}$ & $\begin{array}{l}2.2 .1 \\
(0.28)\end{array}$ & $\begin{array}{l}2.2 .2 \\
(0.49)\end{array}$ & $\begin{array}{l}2.2 .3 \\
(0.23)\end{array}$ & $\begin{array}{l}2.3 .1 \\
(0.30)\end{array}$ & \begin{tabular}{|l|}
2.3 .2 \\
$(0.30)$
\end{tabular} & \begin{tabular}{|l|}
2.3 .3 \\
$(0.40)$
\end{tabular} \\
\hline $\mathrm{BC}$ & 5.57 & $\varnothing$ & 1.75 & 5.81 & 3.51 & 4.08 & & & & & & & & & \\
\hline $\mathrm{B}_{\mathrm{a}}$ & 0.523 & $\varnothing$ & 0.917 & 0.770 & 0.878 & 0.865 & & & & & & & & & \\
\hline
\end{tabular}

In order to gain a clear deviation level, the normalized BC is substituted into the membership functions $\mu_{1}(\mathrm{x})$ :

$$
\mu_{1}(\mathrm{x})=\frac{1}{2} \cos \pi \cdot\left(\mathrm{B}_{\mathrm{a}}-\mathrm{B}_{1}\right)+\frac{1}{2}
$$

where $B_{1}\{1=I, I I, I I I, I V, V\}$ are the normalized values of the quality level. Therefore, a fuzzily expressed situation of overall quality deviation at every milestone can be expressed in the following way:

$$
\left\{\begin{array}{l}
\mathrm{D}_{1.1 .1}=\frac{0.536}{\mathrm{I}}+\frac{0.822}{\mathrm{II}}+\frac{0.961}{\mathrm{III}}+\frac{0.998}{\mathrm{IV}}+\frac{0.464}{\mathrm{~V}} \\
\mathrm{D}_{1.1 .2 .}=\varnothing \\
\mathrm{D}_{1.2 .}=\frac{0983}{\mathrm{I}}+\frac{0.967}{\mathrm{II}}+\frac{0.834}{\mathrm{III}}+\frac{0.629}{\mathrm{IV}}+\frac{0.017}{\mathrm{~V}} \\
\mathrm{D}_{1.3 .1}=\frac{0.875}{\mathrm{I}}+\frac{0.998}{\mathrm{II}}+\frac{0.965}{\mathrm{III}}+\frac{0.831}{\mathrm{IV}}+\frac{0.125}{\mathrm{~V}} \\
\mathrm{D}_{1.3 .2}=\frac{0.964}{\mathrm{I}}+\frac{0.985}{\mathrm{II}}+\frac{0.877}{\mathrm{III}}+\frac{0.687}{\mathrm{IV}}+\frac{0.036}{\mathrm{~V}} \\
\mathrm{D}_{1.3 .3}=\frac{0.956}{\mathrm{I}}+\frac{0.990}{\mathrm{II}}+\frac{0.890}{\mathrm{III}}+\frac{0.706}{\mathrm{IV}}+\frac{0.044}{\mathrm{~V}}
\end{array}\right.
$$

In accordance with the principle of maximum membership degree, the real-time overall quality deviation status in every milestone is shown in Table $\mathbf{8}$ :

Table 8. The real-time overall quality deviation status of subgrade and foundation engineering stage.

\begin{tabular}{|c|c|c|c|c|c|c|}
\hline Milestone & 1.1 .1 & 1.1 .2 & 1.2 & 1.3 .1 & 1.3 .2 & 1.3 .3 \\
\hline Overall quality deviation level & IV & $\varnothing$ & I & II & II & II \\
\hline
\end{tabular}

This result agrees with the actual project situation. In the actual situation, construction schedule basically went according to plan. However, due to the contractor's misunderstanding of the quality requirements and the supervisor's ignorance, project quality was out of control at the beginning of construction, even lower than the critical requirements. After milestone 1.1.2, owners and supervisor identified these quality problems during a routine inspection. Through communication with the contractor and taking remedial measures, such as re-work and maintenance, the project quality improved significantly.

\section{CONCLUSION}

In this paper, an approach for real-time monitoring objective deviation and measuring deviation level in an engineering project was presented. Real-time monitoring is emphasized in this paper, the sensitivity and dynamic, of management have gained increasing importance in the construction of industry. The following conclusions or achievements can be obtained from the above research.

1. Compared with other related researches that mainly focus on single objective management, this research focused more on the comprehensiveness of monitoring scope. Monitoring the real-time situation of all the objectives in one model enable the project manager to carry out management and decision-making in a more macro perspective. It can also save the management resources.

2. Some method about project objective management (for example, CPM) mainly focuses on the planning phase 
and the executed result. This research innovatively built the real-time monitor grid structure in level, milestone, and objective dimensions. The grid structure positions the monitoring point into the whole project process, enhances the timeliness of finding deviations, and eliminates the blind area of the project monitor.

3. This research analyzed the characteristics of engineering project objectives, and observed that the main project objectives can be divided into two classes: MO and FO; each kind of objective has similarity in the buffer analysis. This classification made it possible to real-time monitor all the main objectives in one model.

4. Compared with some objective early-warning researches that needs training data set and black box calculation (for example, BP neural network). This research obtained the objective real-time state and deviation level by observing the $\mathrm{BC}$ variation, the calculation and analysis processes are easy to understand, and it is convenient for project managers to apply the research results.

The further research work will be concentrated on the application of their findings to more real projects and refine them for more case-specific settings to enhance the findings, increase the applicability of the method to a widely range of projects. In addition, we will do our best to enhance the practical applicability of the grid monitoring model. The current research results are expected to be integrated into an engineering project grid monitor information system, which will enable project managers and contractors to use this model more effectively.

\section{CONFLICT OF INTEREST}

The authors confirm that this article content has no conflict of interest.

\section{ACKNOWLEDGEMENTS}

Declared none.

\section{REFERENCES}

[1] M. Parsaee, P. Motealleh, and M. Parva, "Interactive architectural approach (interactive architecture): An effective and adaptive process for architectural design", Hous. Build. Natl. Res. Cent. J., pp. 1-10, 2015. [Article in Press]

[2] Y.N. Wu, Y. Huang, and Q. Wang, "The pre-supervision of safety and environment management in government investment project", J. Wuhan Univ. Technol. (Soc. Sci. Ed.), vol. 25, pp. 309-314, 2012.

[3] J.F. Li, and X. Liu, "Engineering project saticfaction evaluation based on grey clustering", Technoecon. Manag. Res., pp. 12-16, 2011.

[4] P.D. Galloway, "Survey of the construction industry relative to the use of CPM scheduling for construction projects", J. Constr. Eng. Manage., vol. 132, pp. 697-711, 2006.

[http://dx.doi.org/10.1061/(ASCE)0733-9364(2006)132:7(697)]

[5] G. D. Ji, Y. N. Wu, and Q. O, "The research on optimization of earned value management method in engineering budget management", Civil Eng. J., vol. 9, pp. 369-375, 2015. [http://dx.doi.org/10.2174/1874149501509010515]

[6] E. Westerveld, "The Project Excellence Model: Linking success criteria and critical success factors", Int. J. Proj. Manag., vol. 21, pp. 411-418, 2003.

[http://dx.doi.org/10.1016/S0263-7863(02)00112-6]

[7] A.A. Abdullah, H.A. Rahman, Z. Harun, A.M. Alashwal, and A.M. Beksin, "Literature mapping: a bird's eye view on classification of factors influencing project success", African J. Bus. Manag., vol. 4, pp. 4174-4182, 2010.

[8] S. Monghasemi, R.N. Mohammad, and A.K. Mohammad, "A novel multi criteria decision making model for optimizing time-cost-quality trade-off problems in construction projects", Expert Syst. Appl., vol. 42, pp. 3089-3104, 2015.

[http://dx.doi.org/10.1016/j.eswa.2014.11.032]

[9] J. Ramon San Cristobal, "Time, cost, and quality in a road building project", J. Constr. Eng. Manage., vol. 135, pp. 1271-1274, 2009. [http://dx.doi.org/10.1061/(ASCE)CO.1943-7862.0000094]

[10] S.M. Seyedhoseini, S. Noori, and M.A. Hatefi, "An integrated methodology for assessment and selection of the project risk response actions", Risk Anal., vol. 29, no. 5, pp. 752-763, 2009.

[http://dx.doi.org/10.1111/j.1539-6924.2008.01187.x] [PMID: 19144068]

[11] A. Chervenak, I. Foster, C. Kesselman, C. Salisbury, and S. Tuecke, "The data grid: Towards an architecture for the distributed management and analysis of large scientific datasets", J. Netw. Comput. Appl., vol. 23, pp. 187-200, 2000. [http://dx.doi.org/10.1006/jnca.2000.0110]

[12] I. Foster, and C. Kesselman, The Grid: Blueprint for a New Computing Infrastructure., Morgan Kaufmann: San Mateo, CA, 1999.

[13] K. Gor, R.A. Dheepak, S. Ali, L. Alves, N. Arurkar, I. Gupta, A. Chakrabarti, A. Sharma, and S. Sengupta, "Scalable enterprise level workflow and infrastructure management in a grid computing environment", IEEE Int. Symp. Cluster Comput. Grid, vol. 1 and 2, pp. 661-667, 2005. 
[14] X.J. Yue, and H.J. Fan, "The development of grid technology in the Internet and policy in china", Sci. Technol. Prog. Policy, vol. 14, pp. 144-146, 2003.

[15] S.Y. Zheng, H. Xu, and H.C. Wang, "A survey of grid and grid management", Syst. Eng., vol. 3, pp. 1-7, 2005.

[16] M.X. Li, "Intel: grid marketing takes root in China market - visit Intel China regional sales director Li Xiang", Twice China, vol. 6, pp. 10-11, 2007. Available at: http://www.cnki.com.cn/Article/CJFDTotal-DQPJ200706008.htm

[17] J. Zhao, "Industrial grid management practice", Chin. Vocat. Tech. Educ., vol. 30, p. 60, 2007.

[18] P. Chen, "An analysis on digital urban management model", J. Peking Univ. (Philos. Soc. Sci.), vol. 43, pp. 142-148, 2006.

[19] T.N. Nguyen, H. Goto, H. Takahashi, S. Yoshida, and Y. Takei, "Critical chain project management based on a max-plus linear representation for determining time buffers in multiple projects", J. Adv. Mech. Des. Syst. Manuf., vol. 6, pp. 715-727, 2012. [http://dx.doi.org/10.1299/jamdsm.6.715]

[20] M. Bevilacqua, F.E. Ciarapica, and G. Mazzuto, "Critical chain and theory of constraints applied to yachting shipbuilding: A case study", Int. J. Project Organ. Manage., pp. 379-397, 2015.

[21] L.D. Long, and A. Ohsato, "Fuzzy critical chain method for project scheduling under resource constraints and uncertainty", Int. J. Proj. Manag., vol. 26, pp. 688-698, 2008.

[http://dx.doi.org/10.1016/j.ijproman.2007.09.012]

[22] X. Hu, N. Cui, E. Demeulemeester, and L. Bie, "Incorporation of activity sensitivity measures into buffer management to manage project schedule risk", Eur. J. Oper. Res., vol. 249, pp. 717-727, 2016. [http://dx.doi.org/10.1016/j.ejor.2015.08.066]

[23] K.T. Yeo, and J.H. Ning, "Managing uncertainty in major equipment procurement in engineering projects", Eur. J. Oper. Res., vol. 171, pp. $123-134,2006$. [http://dx.doi.org/10.1016/j.ejor.2004.06.036]

[24] J. Colin, and M. Vanhoucke, "A comparison of the performance of various project control methods using earned value management systems", Expert Syst. Appl., vol. 42, pp. 3159-3175, 2015. [http://dx.doi.org/10.1016/j.eswa.2014.12.007]

[25] B.J. Marcianak, Encyclopedia of Software Engineering, John Wiley Sons: US, 2002. [http://dx.doi.org/10.1002/0471028959]

[26] K. Bergner, and J. Friedrich, "Using project procedure diagrams for milestone planning", New Model. Concepts Today's Softw. Process., vol. 6195, pp. 88-99, 2010. [http://dx.doi.org/10.1007/978-3-642-14347-2_9]

[27] H. Malinen, "Project management by results", Int. J. Proj. Manag., vol. 2, pp. 207-210, 1984. [http://dx.doi.org/10.1016/0263-7863(84)90036-X]

[28] G. Girmscheid, "Construction production theory - Planning and control of the construction production process", Bauingenieur, vol. 83, pp. 36-48, 2008.

[29] B.G. Hwang, and E.S. Lim, "Critical success factors for key project players and objectives: case study of Singapore", J. Constr. Eng. Manage., vol. 139, pp. 204-215, 2013. [http://dx.doi.org/10.1061/(ASCE)CO.1943-7862.0000597]

[30] T. Busch, "Attitudes towards management by objects: An empirical investigation of self-efficacy and goal commitment", Scand. J. Manage., vol. 14, pp. 3289-3299, 1998. [http://dx.doi.org/10.1016/S0956-5221(97)00035-3]

[31] Y.C. Li, Y. Yu, and J. Zhao, "Construction system reliability analysis based on improved firefly algorithm", Civil Eng. J., vol. 10, pp. 189-199, 2016. [http://dx.doi.org/10.2174/1874149501610010189]

[32] K. Yaghootkar, and N. Gil, "The effects of schedule-driven project management in multi-project environments", Int. J. Proj. Manag., vol. 30, pp. 127-140, 2012. [http://dx.doi.org/10.1016/j.ijproman.2011.02.005]

[33] T.W. Liao, P.J. Egbelu, B.R. Sarker, and S.S. Leu, "Metaheuristics for project and construction management - A state-of-the-art review", Autom. Construct., vol. 20, pp. 491-505, 2011. [http://dx.doi.org/10.1016/j.autcon.2010.12.006]

(C) Dong et al.; Licensee Bentham Open

This is an open access article licensed under the terms of the Creative Commons Attribution-Non-Commercial 4.0 International Public License (CC BY-NC 4.0) (https://creativecommons.org/licenses/by-nc/4.0/legalcode), which permits unrestricted, non-commercial use, distribution and reproduction in any medium, provided the work is properly cited. 